\title{
Dosimetric Properties of Thulium-doped Strontium Aluminoborate Glasses
}

\author{
Naoki Kawano, ${ }^{1 *}$ Noriaki Kawaguchi, ${ }^{2}$ Go Okada, ${ }^{2}$ \\ Yutaka Fujimoto, ${ }^{3}$ and Takayuki Yanagida ${ }^{2}$ \\ ${ }^{1}$ Graduate School of Engineering Science, Akita University, \\ 1-1 Tegata-Gakuen-machi, Akita 010-8502, Japan \\ ${ }^{2}$ Graduate School of Materials Science, Nara Institute of Science and Technology (NAIST), \\ 8916-5 Takayama, Ikoma 630-0192, Japan \\ ${ }^{3}$ Graduate School of Engineering, Tohoku University, \\ 6-6-07 Aoba, Aramaki, Sendai 980-8579, Japan
}

(Received January 16, 2018; accepted March 9, 2018)

Keywords: dosimeter, thermoluminescence, Tm, scintillator, luminescence

We investigated the photoluminescence (PL), scintillation, and dosimetric properties of strontium aluminoborate glasses with different thulium (Tm) concentrations of 0.1, 0.5, 1.0, and $5.0 \%$. The Tm-doped glasses were synthesized by the conventional melt-quenching technique. In the PL and scintillation spectra, the Tm-doped samples showed a sharp peak at $460 \mathrm{~nm}$ due to the $4 \mathrm{f}-4 \mathrm{f}\left({ }^{1} \mathrm{D}_{2} \rightarrow{ }^{3} \mathrm{~F}_{4}\right)$ transitions of $\mathrm{Tm}^{3+}$. Among the samples tested, the $0.5 \%$ Tm-doped sample exhibited the highest intensity in PL and scintillation. In thermally stimulated luminescence (TSL), the Tm-doped samples showed a broad glow peak around $100{ }^{\circ} \mathrm{C}$ after X-ray irradiation of $10000 \mathrm{mGy}$. The $0.5 \% \mathrm{Tm}$-doped sample also showed the highest TSL intensity. Furthermore, the $0.1-1.0 \%$ Tm-doped samples exhibited a linear response against X-ray doses over a range of $10^{-1}-10^{4} \mathrm{mGy}$.

\section{Introduction}

Radiation dosimetric methods have attracted much attention for decades owing to their application in many fields such as individual radiation monitoring, ${ }^{(1)}$ medicine, ${ }^{(2)}$ and space. ${ }^{(3)}$ The fundamental requirements of dosimetric properties are high sensitivity, dose linearity, energy response, and low fading. ${ }^{(4)}$ Furthermore, in individual radiation monitoring, the effective atomic number of materials used in dosimeter is expected to be close to that of biological tissue $\left(Z_{\text {eff }}=7.35-7.65\right)$ from the viewpoint of bioequivalence. ${ }^{(5)}$ In general, radiation dosimetric methods utilize inorganic phosphors, which demonstrate radiation-induced luminescence phenomena: thermally stimulated luminescence (TSL), optically stimulated luminescence (OSL), and radio-photoluminescence (RPL). To date, various materials such as $\mathrm{LiF}$ doped with $\mathrm{Mg}, \mathrm{Cu}, \mathrm{P}, \mathrm{Al}_{2} \mathrm{O}_{3}$ doped with $\mathrm{C}$, and $\mathrm{NaPO}_{3}-\mathrm{Al}\left(\mathrm{PO}_{3}\right)_{3}$ doped with $\mathrm{Ag}$ have been used in practice. ${ }^{(4)}$

*Corresponding author: e-mail: n-kawano@gipc.akita-u.ac.jp

http://dx.doi.org/10.18494/SAM.2018.1921 
Recently, borate oxide glasses have been focused upon as TSL materials. Borate oxide is a good glass-network former owing to its high bond strength and low melting point, and borate oxide glasses have high accommodation capability with rare-earth oxides and low effective atomic number. For example, $\mathrm{Li}_{2} \mathrm{~B}_{4} \mathrm{O}_{7}$ doped with $\mathrm{Cu}$ showed TSL sensitivity much higher than that of a commercial dosimeter (TLD-100), ${ }^{(6,7)}$ and $\mathrm{SrB}_{4} \mathrm{O}_{7}$ exhibited a sensitivity equivalent to that of TLD-700. ${ }^{(8)}$ In addition, our research group has investigated aluminoborate glasses with the inclusion of $\mathrm{Mg}, \mathrm{Ca}$, and $\mathrm{Sr}$ as host constituents. ${ }^{(9-11)}$ Strontium aluminoborate glasses doped with $\mathrm{Ce}$ exhibited high TSL sensitivity and covered an X-ray dose range of $10^{-1}-10^{4}$ mGy. ${ }^{(10)}$ As these examples have shown, borate oxide glasses are one of the potential materials for dosimeter applications.

In this study, we synthesized strontium aluminoborate glasses doped with various concentrations of thulium (Tm) as luminescent centers by the conventional melt-quenching technique. To the best of our knowledge, no studies have reported the dosimetric properties of Tm-doped strontium aluminoborate glasses. Some Tm-doped materials such as Tm-doped $\mathrm{CaSO}_{4}$ and Tm-doped $\mathrm{CaF}_{2}$ exhibited high TSL intensity and good dose response. ${ }^{(5,12)}$ Thus, the TSL sensitivity of the strontium aluminoborate glasses can be enhanced by the incorporation of Tm as a dopant. After the synthesis, we characterized the Tm-doped glasses for dosimeter applications, and the characterization included optical in-line transmittance, PL, scintillation, and TSL. It is important to study both scintillation and TSL properties comprehensively because some materials show a complementary relationship between these two properties. ${ }^{(13,14)}$

\section{Experimental Methods}

Strontium aluminoborate $\left(50 \mathrm{~B}_{2} \mathrm{O}_{3}-15 \mathrm{Al}_{2} \mathrm{O}_{3}-35 \mathrm{SrO}-x \mathrm{Tm}_{2} \mathrm{O}_{3}, x=0-0.5\right)$ glasses doped with different $\mathrm{Tm}$ concentrations were synthesized by the conventional melt-quenching technique. $\mathrm{B}_{2} \mathrm{O}_{3}$ (99.99\%, Furuuchi Chemical), $\mathrm{Al}_{2} \mathrm{O}_{3}$ (99.99\%, Kojundo Chemical Laboratory), $\mathrm{SrCO}_{3}$ (99.99\%, Kojundo Chemical Laboratory), and $\mathrm{Tm}_{2} \mathrm{O}_{3}$ (99.99\%, Rare Metallic) powders were homogeneously mixed in a stoichiometric ratio. Then, the mixture was melted in an alumina crucible inside an electric furnace heated at $1200{ }^{\circ} \mathrm{C}$ for $30 \mathrm{~min}$ under ambient atmosphere. After that, the melt was quenched on a preheated stainless plate at $350{ }^{\circ} \mathrm{C}$. The glass samples obtained were mechanically polished before characterization.

The optical in-line transmittance spectrum was measured using a spectrophotometer (V670, JASCO), which covered the spectral region from 190 to $2700 \mathrm{~nm}$. As a luminescence property, the PL quantum yields ( $Q Y)$ were measured using Quantaurus QY (C11347, Hamamatsu). PL decay curves were measured using Quantaurus $\tau$ (C11367, Hamamatsu). In this measurement, the excitation wavelength was $360 \mathrm{~nm}$, and the monitoring wavelength was $460 \mathrm{~nm}$. As a scintillation property, X-ray-induced luminescence spectra were measured using our original setup. ${ }^{(15)}$ For X-ray irradiation, the X-ray tube was operated by applying a bias voltage of 40 $\mathrm{kV}$ and a tube current of $5.2 \mathrm{~mA}$. The scintillation decay time profile was measured using an afterglow characterization system equipped with a pulse X-ray source. ${ }^{(16)}$ As a TSL property, TSL glow curves were measured using TL-2000 (Nanogray) at a heating rate of $1{ }^{\circ} \mathrm{C} / \mathrm{s}$ over a temperature range of 50 to $490{ }^{\circ} \mathrm{C} .^{(17)}$ 


\section{Result and Discussion}

\subsection{Samples}

Figure 1 shows a photograph of Tm-doped strontium aluminoborate glasses. The thickness of the samples was about $0.9 \mathrm{~mm}$. The check pattern on the back of the Tm-doped samples was clearly observed. The sample color gradually varied from colorless to brown with increasing Tm concentration.

Figure 2 shows in-line transmittance spectra of Tm-doped strontium aluminoborate glasses. The transmittance of the $0.1-1.0 \%$ Tm-doped samples was about $60 \%$ over the $400-1500 \mathrm{~nm}$ range while the transmittance of the $5.0 \% \mathrm{Tm}$-doped sample was about $40 \%$. In addition, the 1.0-5.0\% Tm-doped samples exhibited sharp absorption peaks at 360, 470, 685, 793, and 1210 $\mathrm{nm}$, which were attributed to the $4 \mathrm{f}-4 \mathrm{f}$ transitions of $\mathrm{Tm}^{3+}\left({ }^{3} \mathrm{H}_{6} \rightarrow{ }^{1} \mathrm{D}_{2},{ }^{3} \mathrm{H}_{6} \rightarrow{ }^{1} \mathrm{G}_{4},{ }^{3} \mathrm{H}_{6} \rightarrow{ }^{3} \mathrm{~F}_{3}\right.$, ${ }^{3} \mathrm{H}_{6} \rightarrow{ }^{3} \mathrm{H}_{4}$, and ${ }^{3} \mathrm{H}_{6} \rightarrow{ }^{3} \mathrm{H}_{5}$, respectively). ${ }^{(18)}$ The optical absorption edge of the Tm-doped samples was almost equivalent to that of a nondoped sample from our previous study. ${ }^{(10)}$

\subsection{Photoluminescence properties}

Figure 3 shows PL emission and excitation contour graphs of Tm-doped strontium aluminoborate glasses. An emission peak at $460 \mathrm{~nm}$ was observed in the Tm-doped samples under an excitation wavelength of $360 \mathrm{~nm}$. The emission peak agreed well with that of the absorption peak observed in the in-line transmission spectra in Fig. 2. Furthermore, the emission wavelength coincided with the reported value for other Tm-doped materials. ${ }^{(18,19)}$ Thus, the emission was ascribed to the $4 \mathrm{f}-4 \mathrm{f}\left({ }^{1} \mathrm{D}_{2} \rightarrow{ }^{3} \mathrm{~F}_{4}\right)$ transitions of $\mathrm{Tm}^{3+}$. In addition, the QY values were $0.03(0.1 \% \mathrm{Tm}), 0.06(0.5 \% \mathrm{Tm})$, and $0.01(1.0 \% \mathrm{Tm})$ while a PL signal from the $0.5 \% \mathrm{Tm}$-doped sample could not be detected. The $0.5 \% \mathrm{Tm}$-doped sample exhibited the

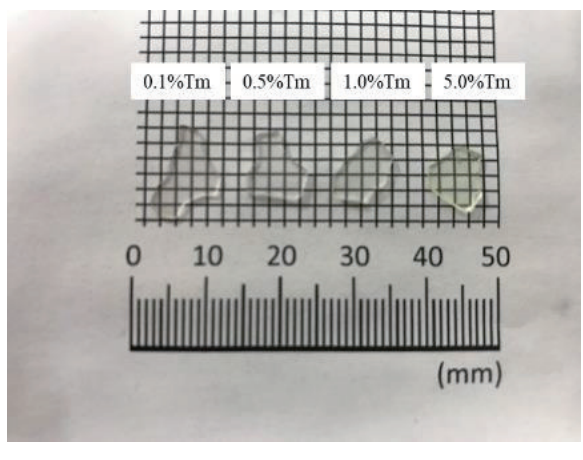

Fig. 1. (Color online) Photograph of Tm-doped strontium aluminoborate glasses.

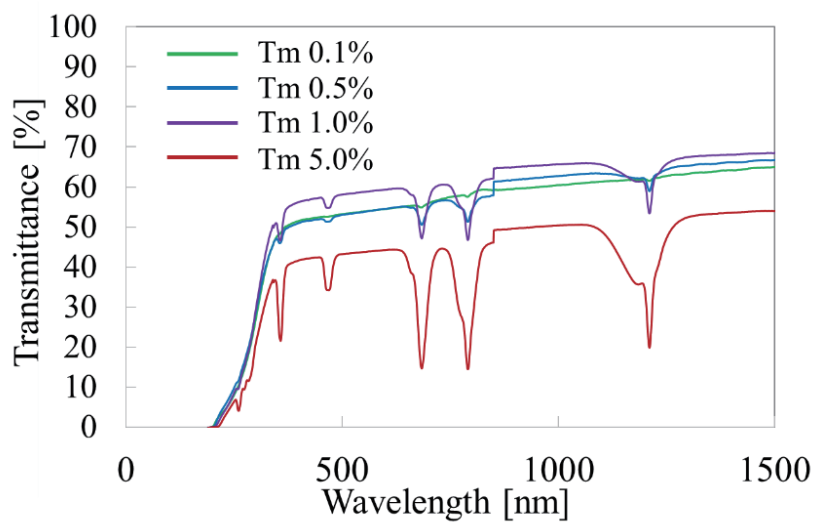

Fig. 2. (Color online) In-line transmittance spectra of Tm-doped strontium aluminoborate glasses. 

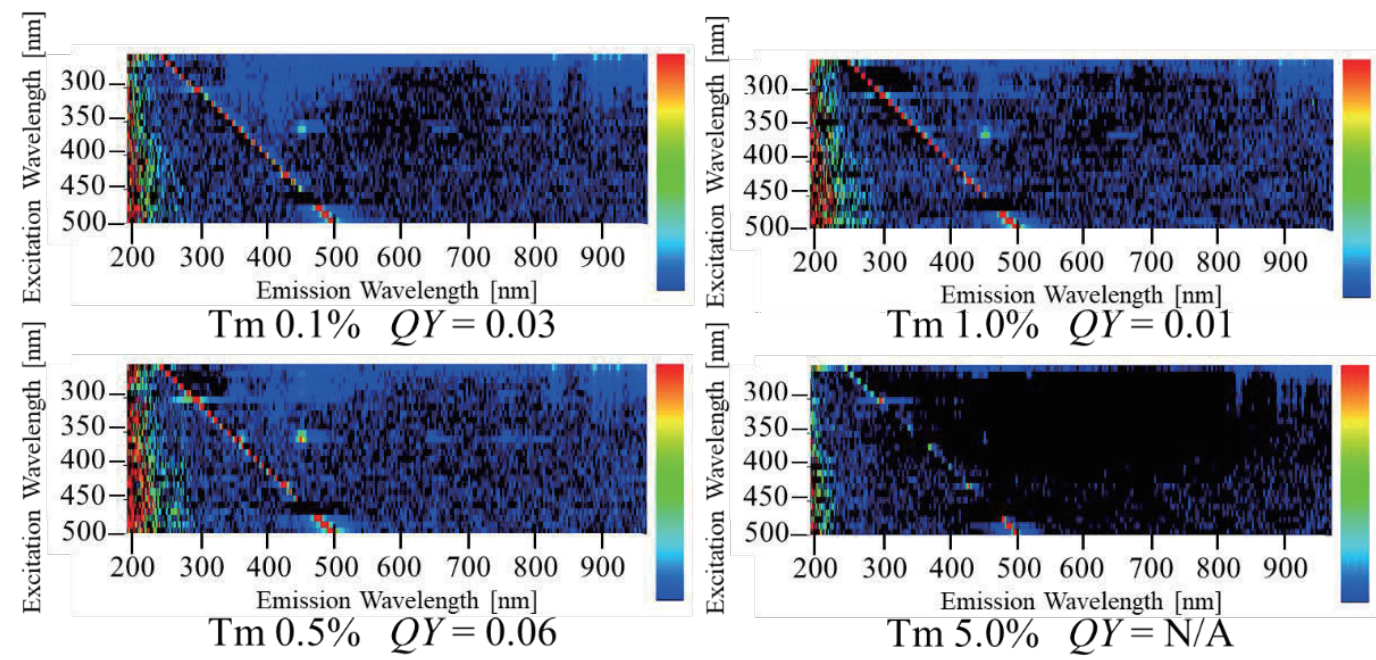

Fig. 3. (Color online) PL emission and excitation contour graphs of Tm-doped strontium aluminoborate glasses.

highest $Q Y$ value among the samples tested. The maximum $Q Y$ value of the $0.5 \% \mathrm{Tm}$-doped sample was lower than that of the $0.3 \%$ Tm-doped $\mathrm{NaPO}_{3}-\mathrm{Al}\left(\mathrm{PO}_{3}\right)_{3}$ glass in a previous study. ${ }^{(19)}$ In addition, the $Q Y$ value decreased with increasing Tm concentrations, perhaps because of concentration quenching.

Figure 4 shows the PL decay time profiles of Tm-doped strontium aluminoborate glasses. In these measurements, the excitation wavelength was $360 \mathrm{~nm}$, and the monitoring wavelength was $460 \mathrm{~nm}$. Each PL decay curve was approximated by an exponential decay function. In this approximation, the component of instrumental response was excluded to obtain the PL decay time. The PL decay times for the Tm-doped samples were $14.0 \mu \mathrm{s}(0.1 \% \mathrm{Tm}), 12.0 \mu \mathrm{s}(0.5 \%$ $\mathrm{Tm}), 10.3 \mu \mathrm{s}(1.0 \% \mathrm{Tm})$, and $9.2 \mu \mathrm{s}(5.0 \% \mathrm{Tm})$. The decay times were almost equivalent to the typical decay time constant of the $4 \mathrm{f}-4 \mathrm{f}\left({ }^{1} \mathrm{D}_{2} \rightarrow{ }^{3} \mathrm{~F}_{4}\right)$ transitions of $\mathrm{Tm}^{3+} \cdot(19)$ The decay time decreased with increasing Tm concentration, perhaps because of concentration quenching.

\subsection{Scintillation properties}

Figure 5 shows the X-ray-induced scintillation spectra of Tm-doped strontium aluminoborate glasses. The Tm-doped samples exhibited emissions at 360 and $460 \mathrm{~nm}$. According to previous studies, ${ }^{(18)}$ the origin of the emissions at 360 and $460 \mathrm{~nm}$ was the $4 \mathrm{f}-4 \mathrm{f}$ transitions of $\mathrm{Tm}^{3+}$ $\left({ }^{1} \mathrm{D}_{2} \rightarrow{ }^{3} \mathrm{H}_{6}\right.$ and ${ }^{1} \mathrm{D}_{2} \rightarrow{ }^{3} \mathrm{~F}_{4}$, respectively). Among the samples tested, the $0.5 \%$ Tm-doped sample exhibited the highest scintillation intensity, which was consistent with the result observed in PL.

Figure 6 shows the X-ray-induced scintillation decay time profiles of Tm-doped strontium aluminoborate glasses. Each decay curve was approximated by the sum of two exponential decay functions. The decay times were 15.8 and $216 \mu$ s $(0.1 \% \mathrm{Tm}), 10.5$ and $123 \mu$ s $(0.5 \%$ $\mathrm{Tm}), 8.9$ and $125 \mu \mathrm{s}(1.0 \% \mathrm{Tm})$, and 9.1 and $204 \mu \mathrm{s}(5.0 \% \mathrm{Tm})$. From previous studies and an effective sensitivity of the equipped photomultiplier tube $(160-650 \mathrm{~nm})$, the origin of the first 

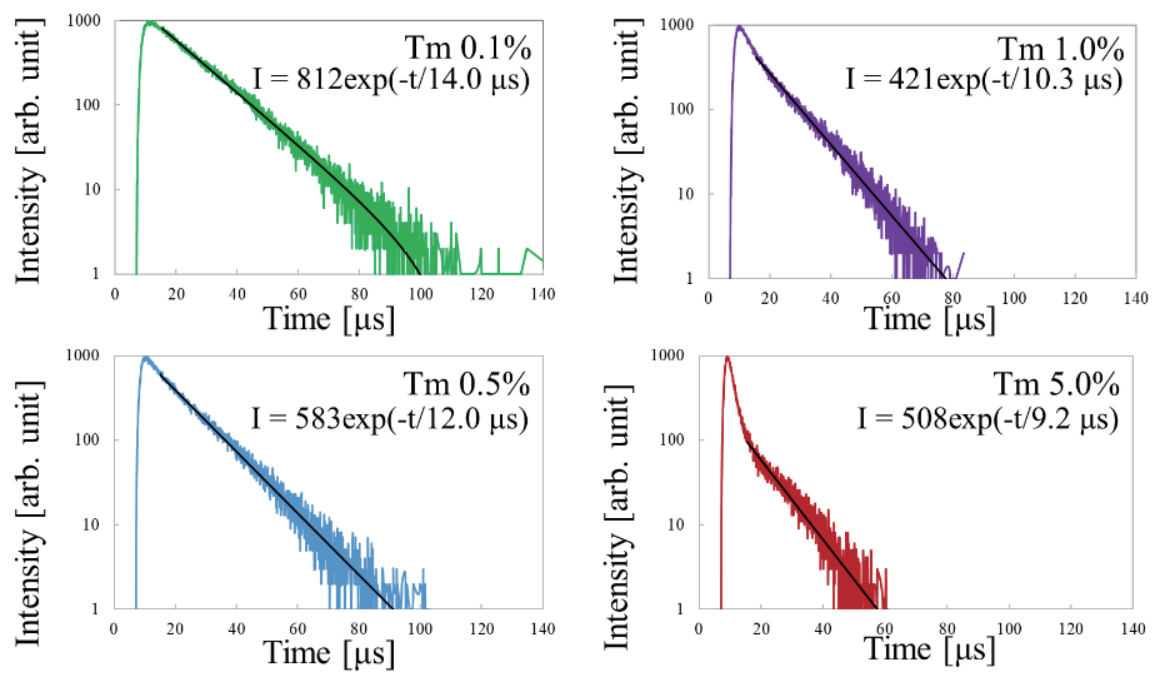

Fig. 4. (Color online) PL decay time profiles of Tm-doped strontium aluminoborate glasses.

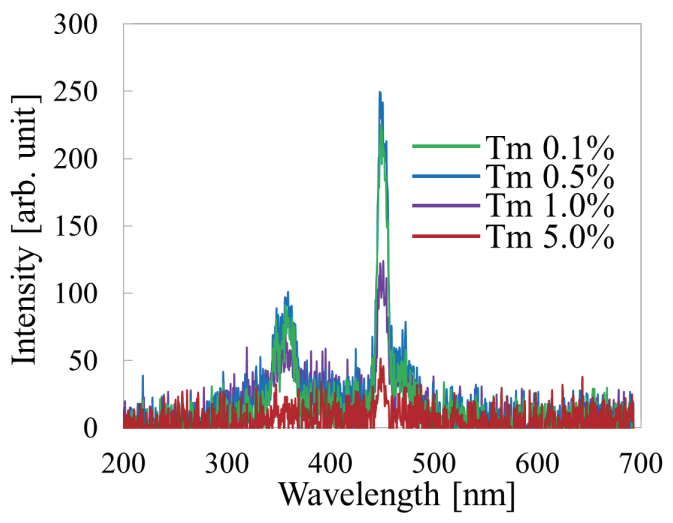

Fig. 5. (Color online) X-ray-induced scintillation spectra of Tm-doped strontium aluminoborate glasses.
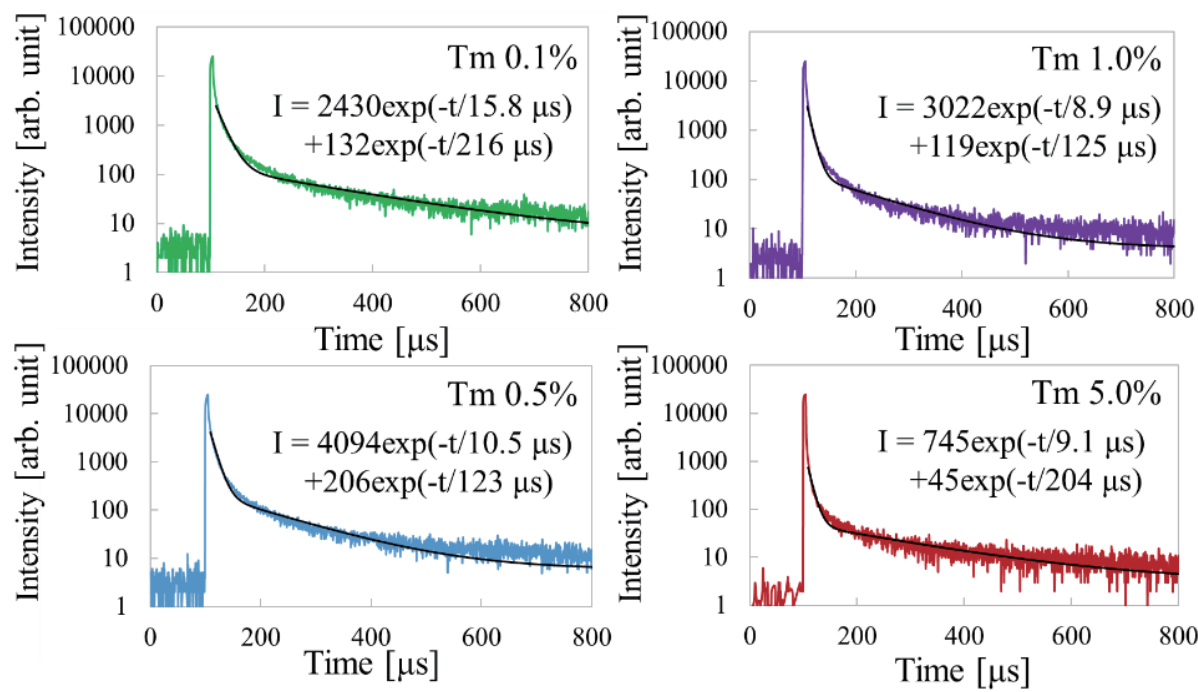

Fig. 6. (Color online) X-ray-induced decay time profiles of Tm-doped strontium aluminoborate glasses. 
component may be the $4 \mathrm{f}-4 \mathrm{f}\left({ }^{1} \mathrm{D}_{2} \rightarrow{ }^{3} \mathrm{H}_{6},{ }^{1} \mathrm{D}_{2} \rightarrow{ }^{3} \mathrm{~F}_{4}\right)$ transitions of $\mathrm{Tm}^{3+},{ }^{18-20)}$ and the origin of the second component may be the $4 \mathrm{f}-4 \mathrm{f}\left({ }^{1} \mathrm{G}_{4} \rightarrow{ }^{3} \mathrm{H}_{6},{ }^{1} \mathrm{G}_{4} \rightarrow{ }^{3} \mathrm{~F}_{4}\right)$ transitions of $\mathrm{Tm}^{3+}$. (18-20) In addition, the decay times of the first component were almost comparable to those observed in other Tm-doped samples such as Tm-doped $\mathrm{Lu}_{3} \mathrm{Al}_{5} \mathrm{O}_{12}{ }^{(21)}$ and $\mathrm{Tm}$-doped $\mathrm{NaPO}_{3}-\mathrm{Al}_{(}\left(\mathrm{PO}_{3}\right)_{3}{ }^{(19)}$ Furthermore, the decay time of the first component became faster with increasing $\mathrm{Tm}$ concentrations, which was consistent with the results observed in PL. In addition, the decay times in scintillation were almost equivalent to those in PL. In general, scintillation decay time is longer than PL decay time owing to additional energy migration processes. This result suggested that scintillation properties may primarily depend on PL processes in the Tm-doped glasses.

\subsection{Dosimetric properties}

Figure 7 shows TSL glow curves of Tm-doped strontium aluminoborate glasses after X-ray irradiation at $10000 \mathrm{mGy}$. The Tm-doped samples exhibited a broad glow peak around $100{ }^{\circ} \mathrm{C}$. The TSL intensity of the $0.5 \%$ Tm-doped samples was the highest among all the samples, so scintillation intensity and TSL intensity exhibited a positive proportionality as with Ce-doped $\mathrm{LiCaAlF}_{6} \cdot{ }^{(14)}$ Furthermore, glow peak temperature, activation energy, and frequency factors were derived by numerical approximations assuming general-order kinetics to evaluate the trap level. ${ }^{(22)}$ The calculated results are summarized in Table 1 . The TSL intensity of the $5.0 \% \mathrm{Tm}$ doped sample was too low to enable these factors to be evaluated accurately. The activation energies and frequency factors were almost constant regardless of the Tm concentration and were almost equivalent to those reported in Ce-doped strontium aluminoborate glasses. ${ }^{(10)}$ Therefore, these results suggested that the origin of the dosimetric trapping centers responsible for TSL may be the glass host. In addition, the low values of the frequency factors suggested that the primary detrapping process of TSL was the tunneling effect.

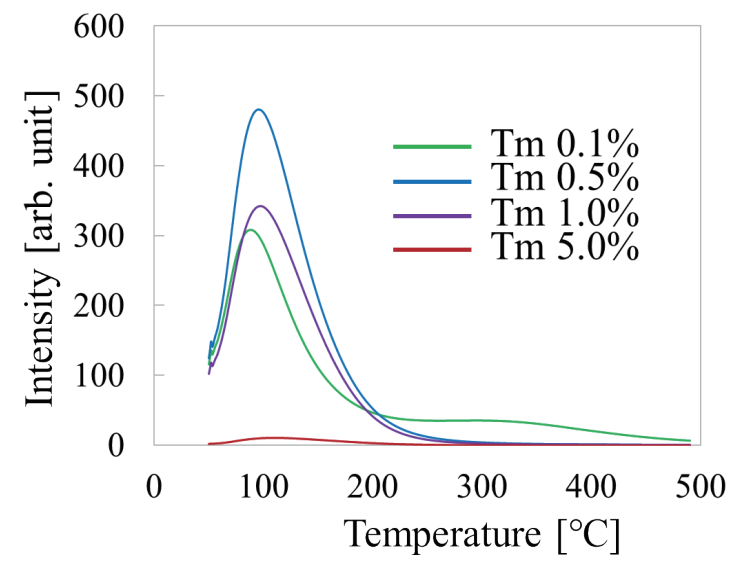

Fig. 7. (Color online) TSL glow curves of Tm-doped strontium aluminoborate glasses after X-ray irradiation at $10000 \mathrm{mGy}$. 
Table 1

Glow peak temperature, activation energies, and frequency factors.

\begin{tabular}{lccc}
\hline & $\begin{array}{c}\text { Peak temperature } \\
\left({ }^{\circ} \mathrm{C}\right)\end{array}$ & $\begin{array}{c}\text { Activation energy } \\
(\mathrm{eV})\end{array}$ & $\begin{array}{c}\text { Frequency factors } \\
\left(\mathrm{s}^{-1}\right)\end{array}$ \\
\hline \multirow{2}{*}{$0.1 \% \mathrm{Tm}$} & 93 & 0.46 & $1.12 \times 10^{5}$ \\
& 165 & 0.55 & $1.10 \times 10^{5}$ \\
\hline \multirow{2}{*}{$0.5 \% \mathrm{Tm}$} & 100 & 0.47 & $1.36 \times 10^{5}$ \\
& 166 & 0.61 & $4.31 \times 10^{5}$ \\
\hline \multirow{2}{*}{$1.0 \% \mathrm{Tm}$} & 102 & 0.47 & $1.26 \times 10^{5}$ \\
& 170 & 0.56 & $1.22 \times 10^{5}$ \\
\hline
\end{tabular}

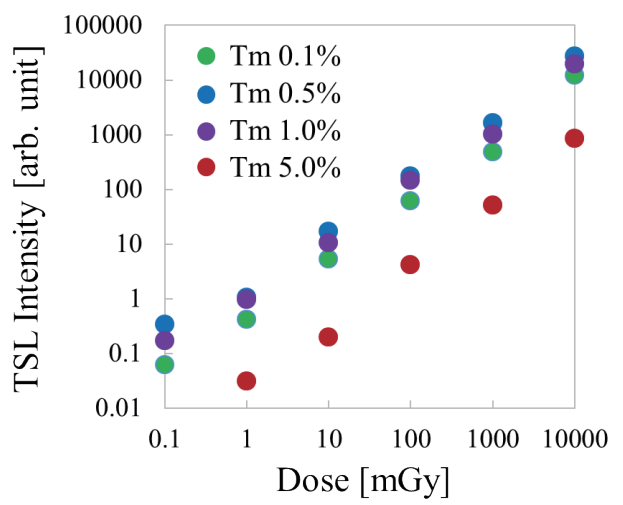

Fig. 8. (Color online) TSL glow curves of Tm-doped strontium aluminoborate glasses.

Figure 8 shows the TSL dose response curves of Tm-doped strontium aluminoborate glasses. The integrated value of a TSL peak around $100{ }^{\circ} \mathrm{C}$ was defined as the TSL intensity. The lowest detection limit of the $0.1-1.0 \%$ Tm-doped samples was confirmed to be $0.1 \mathrm{mGy}$ while the limit of the $5.0 \%$ Tm-doped sample was confirmed to be $1 \mathrm{mGy}$. Furthermore, the $0.1-1.0 \% \mathrm{Tm}$ doped samples exhibited a linear response to X-ray dose over a dose range of $0.1-10000 \mathrm{mGy}$. This dynamic range was comparable to that of Ce-doped strontium aluminoborate glasses reported in our previous study. ${ }^{(10)}$ A linear response with respect to X-ray dose is important because it enables us to measure accurately and easily calibrate the X-ray dose. However, the lowest dose sensitivity $(0.1 \mathrm{mGy})$ was not sufficient compared with TSL dosimeters such as $\mathrm{Al}_{2} \mathrm{O}_{3}: \mathrm{C}$ and $\mathrm{LiF}: \mathrm{Mg}, \mathrm{Cu}, \mathrm{P}^{(4)}$ The TSL sensitivity is expected to be improved by optimizing the host composition and the dopant species.

\section{Conclusion}

Strontium aluminoborate glasses with different concentrations of $\operatorname{Tm}(0.1,0.5,1.0$, and 5.0\%) were synthesized by the conventional melt-quenching technique. The PL, scintillation, and TSL properties of the glasses were investigated. The Tm-doped samples showed an emission at 460 $\mathrm{nm}$ due to the $4 \mathrm{f}-4 \mathrm{f}\left({ }^{1} \mathrm{D}_{2} \rightarrow{ }^{3} \mathrm{~F}_{4}\right)$ transitions of Tm with decay time constants of approximately 9-16 $\mu \mathrm{s}$ in PL and scintillation. Among the samples investigated, the $0.5 \%$ Tm-doped sample showed the highest intensity in PL and scintillation. Furthermore, the $0.5 \%$ Tm-doped sample 
also showed the highest TSL sensitivity after X-ray irradiation of $10000 \mathrm{mGy}$. The TSL intensity of the $0.1-1.0 \%$ Tm-doped samples monotonically increased with an X-ray dose irradiated over $0.1-10000 \mathrm{mGy}$.

\section{Acknowledgments}

This work was supported by Grant-in-Aid for Scientific Research (A) (17H01375), Grantin-Aid for Young Scientists (B) (17K14911), and Grant-in-Aid for Research Activity Start-up (16H06983) from the Ministry of Education, Culture, Sports, Science and Technology of the Japanese government (MEXT) as well as A-STEP from the Japan Science and Technology Agency (JST). The Cooperative Research Project of the Research Institute of Electronics, Shizuoka University, The Taisei Foundation, SEI Group CSR Foundation, Mazda Foundation, Konica Minolta Science and Technology Foundation, NAIST Foundation, and TEPCO Memorial Foundation are also acknowledged.

\section{References}

1 S. W. S. McKeever: Radiat. Meas. 46 (2011) 1336.

2 E. G. Yukihara, P. B. R.Gasparian, G. O. Sawakuchi, C. Ruan, S. Ahmad, C. Kalavagunta, W. J. Clouse, N. Sahoo, and U. Titt: Radiat. Meas. 45 (2010) 658.

3 S. W. S. McKeever: Radiat. Prot. Dosim. 100 (2002) 27.

4 B. C. Bhatt: Radiat. Prot. Environ. 34 (2011) 6.

5 A. J. J. Bos: Nucl. Instrum. Methods Phys. Res., Sect. B 184 (2001) 3.

6 M. Takenaga, O. Yamamoto, and T. Yamashita: Health Phys. 44 (1983) 387.

7 T. K. Gundurao, J. R. Sarwade, and S. V. Moharil: Radiat. Eff. Defects Solids 138 (1996) 177.

8 M. Santiago, A. Lavat, E. Caselli, M. Lester, L. J. Perisinotti, A. K. de Figuereido, F. Spano, and F. Ortega: Phys. Status Solidi A 167 (1998) 233.

9 T. Yahaba, Y. Fujimoto, T. Yanagida, M. Koshimizu, H. Tanaka, K. Saeki, and K. Asai: Nucl. Instrum. Methods Phys. Res., Sect. B 392 (2017) 36.

10 N. Kawano, N. Kawaguchi, G. Okada, Y. Fujimoto, and T. Yanagida: J. Non-Cryst. Solids 482 (2018) 154.

11 D. Nakauchi, G. Okada, Y. Fujimoto, N. Kawano, N. Kawaguchi, and T. Yanagida: Opt. Mater. 72 (2017) 190.

12 B. Marczewska, P. Bilski, M. Budzanowski, P. Olko, and V. Chernov: Radiat. Meas. 33 (2011) 571.

13 T. Yanagida, Y. Fujimoto, K. Watanabe, K. Fukuda, N. Kawaguchi, Y. Miyasaka, and H. Nanto: Radiat. Meas. 71 (2014) 162.

14 T. Yanagida: J. Lumin. 169 (2016) 544.

15 T. Yanagida, K. Kamada, Y. Fujimoto, H. Yagi, and T. Yanagitani: Opt. Mater. 35 (2013) 2480.

16 T. Yanagida, Y. Fujimoto, T. Ito, K. Uchiyama, and K. Mori: Appl. Phys. Express 7 (2014) 062401.

17 T. Yanagida, Y. Fujimoto, N. Kawaguchi, and S. Yanagida: J. Ceram. Soc. Jpn. 121 (2013) 988.

18 L. Macalik, J. Hanuza, D. Jaque, and J. García Solé: Opt. Mater. 28 (2006) 980.

19 T. Kuro, G. Okada, N. Kawaguchi, Y. Fujimoto, H. Masai, and T. Yanagida: Opt. Mater. 62 (2016) 561.

20 Y. Fujimoto, M. Sugiyama, T. Yanagida, S. Wakahara, S. Suzuki, S. Kurosawa, V. Chani, and A. Yoshikawa: Opt. Mater. 35 (2013) 2023.

21 M. Sugiyama, Y. Fujimoto, T. Yanagida, D. Totsuka, and Y. Yokota: Opt. Mater. 34 (2011) 439.

22 G. Kitis, J. M. Gomes-Ros, and J. W. N. Tuyn: J. Phys D: Appl. Phys. 31 (1998) 2636. 